\title{
Dispensed prescriptions for quetiapine and other second- generation antipsychotics in Canada from 2005 to 2012: a descriptive study
}

\author{
Tamara Pringsheim MD MSc, David M. Gardner PharmD MSc
}

\section{Abstract}

Background: The use of antipsychotic drugs, particularly quetiapine, has increased at an unprecedented rate in the last decade, primarily in relation to nonpsychotic indications. This increased use is concerning because of the high rates of metabolic and extrapyramidal side effects and inadequate monitoring of these complications. The purpose of this study was to measure the use of quetiapine and other second-generation antipsychotics by primary care physicians and psychiatrists and the most common diagnoses associated with quetiapine recommendations.

Methods: We analyzed data on antipsychotic use from the IMS Brogan Canadian CompuScript Database and the Canadian Disease and Treatment Index, with a focus on quetiapine. We looked at the number of dispensed prescriptions for second-generation antipsychotics written by primary care physicians and psychiatrists and the diagnoses associated with recommendations for quetiapine from 2005 to 2012.

Results: Between 2005 and 2012, there was a 300\% increase in dispensed prescriptions for quetiapine ordered by family physicians: from 1.04 million in 2005 to 4.17 million in 2012. In comparison, dispensed prescriptions from family physicians for risperidone increased 37.4\%: from 1.39 million in 2005 to 1.91 million in 2012; those for olanzapine increased 37.1\%, from 0.97 million in 2005 to 1.33 million in 2012. Dispensed prescriptions for quetiapine ordered by psychiatrists increased $141.6 \%$ : from 0.87 million in 2005 to 2.11 million in 2012. The top 4 diagnoses associated with quetiapine in 2012 were mood disorders, psychotic disorders, anxiety disorders and sleep disturbances. A 10-fold increase in quetiapine recommendations for sleep disturbances was seen over the study period, with almost all coming from family physicians.

Interpretation: These findings indicate a preferential increase in the use of quetiapine over other antipsychotic drugs and show that most of the increased use is a result of off-label prescribing by family physicians.

I $\mathrm{n}$ the last decade, the use of antipsychotic drugs has increased at an unprecedented rate across all age groups in Canada, primarily in relation to new, nonpsychotic indications and off-label use. ${ }^{1-3}$ Second-generation antipsychotics are preferred by prescribers, mainly because they are associated with a lower risk of movement disorders. ${ }^{4}$ The second-generation antipsychotics, which have been available in Canada since the 1990s, include risperidone, olanzapine, quetiapine, clozapine, ziprasidone, paliperidone, aripiprazole, lurasidone and asenapine. In clinical practice, the use of these drugs varies considerably, especially for olanzapine, which is most commonly used for chronic psychotic disorders; risperidone, with its mixed use for psychosis and among young people with disruptive disorders; and quetiapine, which has become commonplace treatment for mood, anxiety and sleep problems. ${ }^{1,5-7}$ The evidence base for these expanded uses is often insubstantial or, in the case of the use of quetiapine as a hypnotic, limited.

Originally indicated for the treatment of schizophrenia, quetiapine now has Health Canada and US Food and Drug Administration (FDA) approvals for the management of bipolar disorder as well as for major depressive disorder. ${ }^{8,9}$ For major depressive disorder, it is to be reserved for treatment after failure of standard therapies ${ }^{10}$ or as a treatment adjunct. ${ }^{11}$

Competing interests: See the end of the article.

This article has been peer reviewed.

Correspondence to: tmprings@ucalgary.ca

CMAJ Open 2014. DOI:10.9778/cmajo.20140009 
It is not indicated for anxiety or sleep disturbances. Regarding its application for approval to treat generalized anxiety disorder, the FDA raised concerns about its association with risk of long-term metabolic and movement disorders and with sudden cardiac death. ${ }^{12}$ The manufacturer retracted its applications for an anxiety disorder indication several years ago.

Data from British Columbia have shown that quetiapine is the ninth most frequently prescribed medication in the province. Fifty-eight percent of prescriptions in British Columbia were for the $25-\mathrm{mg}$ tablet, suggesting that it is mainly being prescribed for sleep disturbances, rather than psychotic or mood disorders. ${ }^{13}$

Quetiapine and its active metabolite norquetiapine are both potent antihistamines. ${ }^{14}$ This, possibly among other pharmacologic actions, accounts for quetiapine's hypnotic effect and its increasing popularity as a sleeping aid when used at lower doses. ${ }^{15,16}$ At intermediate doses, putative antidepressant and anxiolytic pharmacologic actions become relevant. Norquetiapine and, to a lesser extent, quetiapine are $5-\mathrm{HT}_{1 \mathrm{~A}}$ agonists, and norquetiapine is a moderately potent noradrenaline reuptake inhibitor. However, quetiapine and its several metabolites are pharmacologically diverse and carry risks that make quetiapine a poor choice, based on tolerability and safety concerns, regardless of its efficacy, in the routine management of insomnia, anxiety and depression. ${ }^{4,12}$

We measured the increase in the use of quetiapine and other second-generation antipsychotics by primary care physicians and psychiatrists and investigated the most common diagnoses associated with quetiapine recommendations, including its rate of use for the treatment of mood, psychotic and anxiety disorders as well as sleep disturbances. We focused on quetiapine, as we had noticed in clinical practice an increased frequency of patients taking low doses of this medication in recent years. We suspected that the increase in quetiapine use had surpassed that of the other secondgeneration antipsychotics, because of its reported effects on mood, anxiety and sleep. We also suspected that most prescriptions for quetiapine may have been being written by nonspecialist physicians, who may not have adequate knowledge of the potentially serious adverse effects related to its use. We assessed prescriptions for the other second-generation antipsychotics to provide a means of comparison and a larger context.

\section{Methods}

\section{Data sources}

IMS Brogan is a proprietary source of pharmaco-epidemiologic data. It provides market intelligence to the pharmaceutical and health care industries, and its data products are used by academics, pharmaceutical companies, drug plan administrators and government. The IMS Brogan databases are the only source of population-based data on antipsychotic medications in Canada. Administrative data cannot be used for this purpose because, in most Canadian provinces, records of prescription data are only collected for special population groups (e.g., those covered by publicly funded drug plans), and the extent of coverage differs across provinces. Several national surveys have collected information on medication use (e.g., the National Population Health Survey), but no surveys with an adequate sample size have targeted antipsychotic drugs.

We carried out analyses based on the IMS Brogan Canadian CompuScript Database to determine the quantity of antipsychotic prescriptions per year (2005-2012) by specialty, and we used the Canadian Disease and Treatment Index to estimate the proportion of antipsychotic drugs prescribed for specific diagnoses. The Canadian CompuScript Database contains national prescription data collected in pharmacies at the time prescriptions are filled, including the specialty of the prescribing physician. The data collected from Quebec, Ontario, Alberta, Saskatchewan, Nova Scotia, New Brunswick, Prince Edward Island and Newfoundland and Labrador are tagged with a physician number or name, which allows IMS Brogan to identify the specialty of the prescriber. In British Columbia and Manitoba, national estimates are used as a proxy at the provincial level. Estimates of prescribing rate by specialty are derived through statistical methods that maintain the proportion of physicians in each specialty. More than $60 \%$ of retail pharmacies across Canada report data to IMS Brogan. ${ }^{17}$

\section{Statistical analysis}

For this study, we analyzed the annual number of dispensed prescriptions (filled prescriptions) for quetiapine ordered by primary care physicians and psychiatrists, as well the number of dispensed prescriptions for risperidone, olanzapine, aripiprazole, ziprasidone, clozapine and paliperidone for comparison purposes. We used annual population estimates from Statistics Canada to calculate the number of prescriptions for quetiapine, risperidone and olanzapine per 100000 population from primary care physicians and psychiatrists each year, and the annual percentage change.

We used the Canadian Disease and Treatment Index to evaluate diagnoses associated with recommendations for quetiapine by primary care physicians and psychiatrists. This index collects treatment data from a sample of Canadian office-based physicians $(n=652)$, who constitute a representative sample, both geographically and by specialty, with weighting adjustments made to determine national drug recommendations each year. Each physician participating in the panel completes a record of all patient visits during a 2-day period each quarter (i.e., 4 times a year). The nature of each visit, including the age and sex of the patient, drug recommendation and the therapeutic indication for each drug recommendation are recorded. Physicians are compensated for participation and accuracy. Analyses of the Canadian Disease and Treatment Index in Excel allowed us to characterize the frequency with which physicians recommend antipsychotic medications for specific diagnoses.

\section{Results}

Quetiapine, risperidone and olanzapine were the 3 antipsychotic medications most commonly prescribed by primary 
care physicians and psychiatrists from 2005 to 2012; the other second-generation antipsychotics accounted for fewer than $20 \%$ of prescriptions over this period. Between 2005 and 2012 , there was a $300 \%$ increase in dispensed prescriptions for quetiapine ordered by primary care physicians: from 1.04 million in 2005 to 4.17 million in 2012 (Table 1). In comparison, dispensed prescriptions for risperidone ordered by primary care physicians increased $37.1 \%$, from 1.39 million in 2005 to 1.91 million in 2012; for olanzapine, the increase was $37.1 \%$, from 0.97 million in 2005 to 1.33 million in 2012 (Table 1 and Figure 1). Dispensed prescriptions for quetiapine from primary care physicians surpassed prescriptions for the other 2 medications from 2007 onward. Data from Statistics Canada show that the population of Canada grew $7.8 \%$ during the study period (from 32.24 million in 2005 to 34.75 million in 2012). ${ }^{18}$ In 2005 , primary care physicians ordered 3229 dispensed prescriptions for quetiapine per 100000 Canadians; by 2012, this had increased to 11987 quetiapine prescriptions per 100000 .

The total number and rate of increase of dispensed prescriptions for quetiapine was much higher for primary care physicians than psychiatrists. Dispensed prescriptions for quetiapine by psychiatrists increased $141.6 \%$, from 0.87 million in 2005 to 2.11 million in 2012 (Table 2). Dispensed prescriptions for risperidone increased by $43.3 \%$ and those for olanzapine increased $32.4 \%$ over the same period (Table 2 ). In 2005, psychiatrists were prescribing quetiapine, risperidone and olanzapine at nearly identical rates (Figure 2). By 2012, the rate of use of quetiapine had approximately doubled the rate of the other 2 antipsychotics. In terms of population, the number of dispensed prescriptions for quetiapine from psychiatrists rose from 2709 per 100000 in 2005 to 6072 per 100000 in 2012.

As estimated from the Canadian Disease and Treatment Index, quetiapine recommendations from primary care physicians and psychiatrists increased from 1.15 million in 2005 to 1.92 million in 2012. In 2012, the top 4 diagnoses, accounting for $78.8 \%$ of quetiapine recommendations, were mood disorders, psychotic disorders, anxiety disorders and sleep disturbances (Figures 3 and 4). Quetiapine prescriptions for mood disorders nearly doubled over the study period, mainly because of an increase in recommendations from primary care physicians (Figure 3). For psychosis, overall use decreased, because of fewer recommendations by psychiatrists (Figure 4). For the treatment of anxiety disorders, recommendations for quetiapine more than doubled, primarily as a result of increased prescribing by primary care physicians (Figure 3). A 10 -fold increase in quetiapine recommendations for sleep disturbances was seen over the 7-year study period, with almost all recommendations coming from primary care physicians (Figure 3).

\section{Interpretation}

These findings indicate a large and preferential increase in the use of quetiapine over other second-generation antipsychotics in Canada. They show that quetiapine's expanded use is mostly a result of an increase in prescribing by primary care physicians for nonpsychotic disorders. Our CompuScript analysis shows that over $50 \%$ of filled antipsychotic prescriptions in Canada in

\begin{tabular}{|c|c|c|c|c|c|c|c|c|}
\hline Measure & 2005 & 2006 & 2007 & 2008 & 2009 & 2010 & 2011 & 2012 \\
\hline $\begin{array}{l}\text { Population of } \\
\text { Canada }\end{array}$ & 32242364 & 32570505 & 32887928 & 33245773 & 33628571 & 34005274 & 34342780 & 34754312 \\
\hline \multicolumn{9}{|l|}{ Quetiapine } \\
\hline No. prescriptions & 1040948 & 1426202 & 1909052 & 2313005 & 2652720 & 3260476 & 3782821 & 4166110 \\
\hline $\begin{array}{l}\text { Prescriptions per } \\
100000 \text { people }\end{array}$ & 3229 & 4369 & 5805 & 6957 & 7888 & 9588 & 11015 & 11987 \\
\hline Annual change, \%* & & 35.3 & 32.9 & 19.8 & 13.4 & 21.6 & 14.9 & 8.8 \\
\hline \multicolumn{9}{|l|}{ Risperidone } \\
\hline No. prescriptions & 1390177 & 1516660 & 1755263 & 1819043 & 1821225 & 1971661 & 1972659 & 1906133 \\
\hline $\begin{array}{l}\text { Prescriptions per } \\
100000 \text { people }\end{array}$ & 4312 & 4657 & 5337 & 5472 & 5416 & 5798 & 5744 & 5485 \\
\hline Annual change, \%* & & 8.0 & 14.6 & 2.5 & -1.0 & 7.1 & -1.0 & -4.5 \\
\hline \multicolumn{9}{|l|}{ Olanzapine } \\
\hline No. prescriptions & 966296 & 1059073 & 1214121 & 1306724 & 1319171 & 1368176 & 1363638 & 1328802 \\
\hline $\begin{array}{l}\text { Prescriptions per } \\
100000 \text { people }\end{array}$ & 2997 & 3252 & 3692 & 3968 & 3923 & 4023 & 3971 & 3823 \\
\hline Annual change, $\%^{*}$ & & 8.5 & 13.5 & 7.5 & -1.1 & 2.5 & -1.3 & -3.7 \\
\hline
\end{tabular}




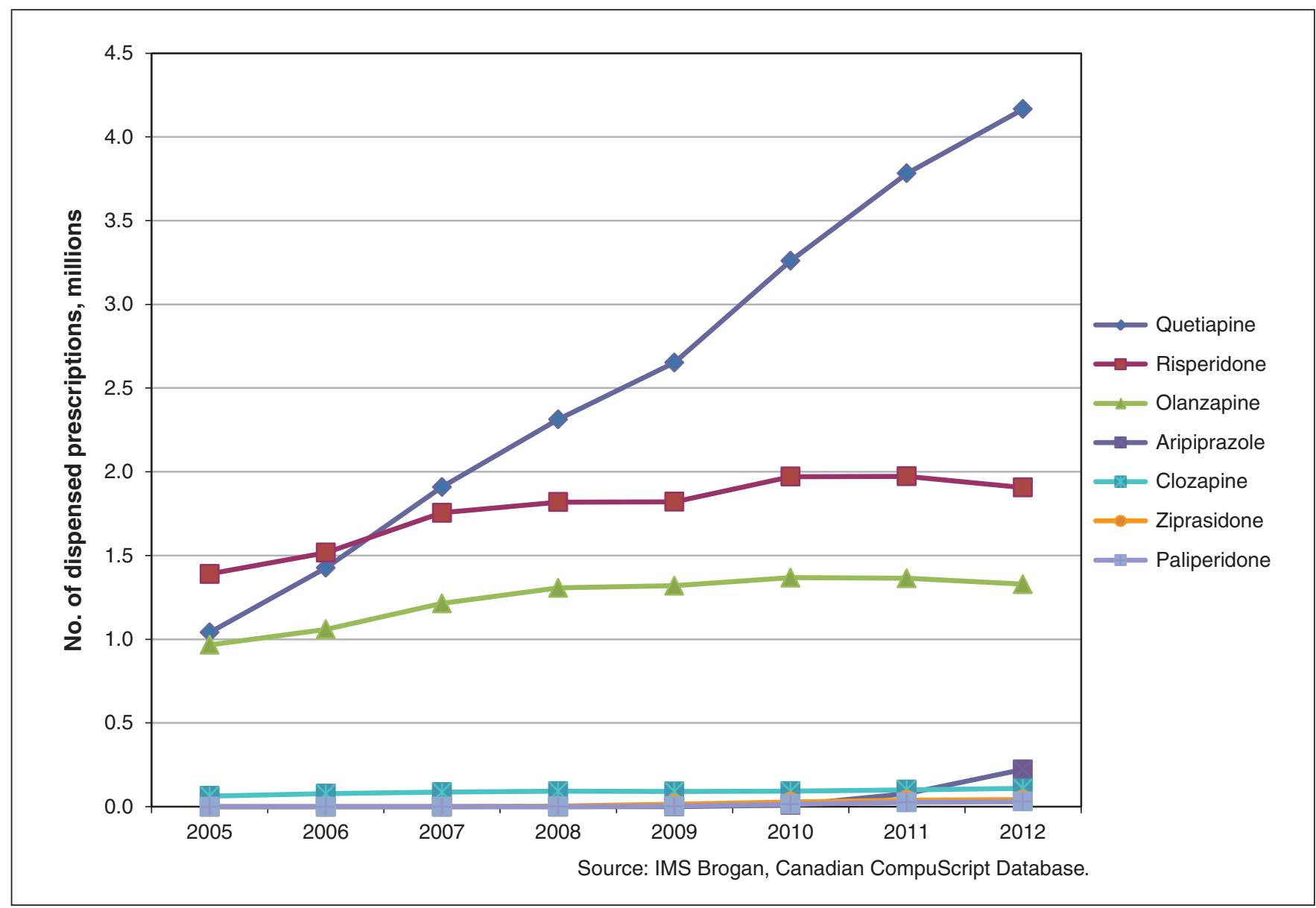

Figure 1: Number of prescriptions for second-generation antipsychotics ordered by primary care physicians, 2005-2012.

Table 2: Dispensed prescriptions for the 3 antipsychotic drugs ordered most frequently by Canadian psychiatrists, 2005-2012

\begin{tabular}{|c|c|c|c|c|c|c|c|c|}
\hline & 2005 & 2006 & 2007 & 2008 & 2009 & 2010 & 2011 & 2012 \\
\hline $\begin{array}{l}\text { Population of } \\
\text { Canada }\end{array}$ & 32242364 & 32570505 & 32887928 & 33245773 & 33628571 & 34005274 & 34342780 & 34754312 \\
\hline \multicolumn{9}{|l|}{ Quetiapine } \\
\hline No. prescriptions & 873369 & 1051645 & 1249125 & 1424893 & 1588240 & 1832978 & 2003085 & 2110329 \\
\hline $\begin{array}{l}\text { Prescriptions per } \\
100000 \text { people }\end{array}$ & 2709 & 3229 & 3798 & 4286 & 4723 & 5390 & 5833 & 6072 \\
\hline Annual change, \%* & & 19.2 & 17.6 & 12.8 & 10.2 & 14.1 & 8.2 & 4.1 \\
\hline \multicolumn{9}{|l|}{ Risperidone } \\
\hline No. prescriptions & 736150 & 817650 & 911802 & 987363 & 998010 & 1081290 & 1112243 & 1055298 \\
\hline $\begin{array}{l}\text { Prescriptions per } \\
100000 \text { people }\end{array}$ & 2283 & 2510 & 2772 & 2970 & 2968 & 3180 & 3239 & 3036 \\
\hline Annual change, \%* & & 9.9 & 10.4 & 7.1 & -0.1 & 7.1 & 1.9 & -6.3 \\
\hline \multicolumn{9}{|l|}{ Olanzapine } \\
\hline No. prescriptions & 751717 & 797554 & 876468 & 945572 & 936843 & 1006372 & 1010235 & 995478 \\
\hline $\begin{array}{l}\text { Prescriptions per } \\
100000 \text { people }\end{array}$ & 2331 & 2449 & 2665 & 2844 & 2786 & 2959 & 2942 & 2864 \\
\hline Annual change, \%* & & 5.1 & 8.8 & 6.7 & -2.0 & 6.2 & -0.6 & -2.7 \\
\hline
\end{tabular}


2012 were for quetiapine and that most came from primary care physicians. Our analyses of the Canadian Disease and Treatment Index data show how the use of quetiapine has changed over time. Although there has been a gradual decline in its recommendation for psychosis, other uses have increased steadily, and this trend has been observed by others. ${ }^{19,20}$

The increase in off-label use of quetiapine preceded its regulatory approval as a treatment for depression. Health Canada approved quetiapine for bipolar disorder in $2008 .{ }^{10} \mathrm{It}$ was approved as an indication for major depression (when standard therapies failed) by Health Canada in 2009. ${ }^{10,11}$ In their systematic review, Komossa and colleagues ${ }^{21}$ suggested that quetiapine be reserved for second- or third-line treatment of depression. An end-of-study difference of 2.52 (95\% confidence interval [CI $1.37-3.66)$ points favouring quetiapine over placebo was found when studies using the Hamilton Depression Rating Scale were combined. Numbers needed to treat to achieve a response or remission and numbers needed to harm (i.e., discontinuation due to adverse effects) were approximately 8,17 and 11 , respectively, versus placebo. When quetiapine was used as an adjunct to unsuccessful antidepressant treatment, the corresponding numbers needed to treat or harm were estimated to be 10,8 and 12 , respectively. The only direct comparison with an antidepressant was with duloxetine, which may be less effective and less tolerable than other antidepressants; ${ }^{22}$ that study found no differences in efficacy between treatment and control groups, but overall tolerability was reduced among those taking quetiapine. ${ }^{23}$

The extent of quetiapine use to treat anxiety is unprecedented for an antipsychotic. Although several small randomized trials ${ }^{24,25}$ were completed and published earlier, the first large randomized controlled trial (RCT) of quetiapine for anxiety was published in a peer-reviewed journal in $2010^{26}$ followed by 4 others ${ }^{27-30}$ in the following years. A systematic review $^{31}$ of RCTs of quetiapine for anxiety found it to be clinically efficacious for generalized anxiety; however, its overall tolerability was poor. Quetiapine improved scores on the Hamilton anxiety rating scale by 2.6 (95\% CI $1.2-4.0)$ points more than placebo. Numbers needed to treat or harm to obtain a response, remission or discontinuation due to adverse effects were 6, 10 and 8, respectively. In head-to-head compar isons with paroxetine $(20 \mathrm{mg} / \mathrm{d})$ and escitalopram $(10 \mathrm{mg} / \mathrm{d})$, there were no differences in efficacy but quetiapine was less well tolerated. ${ }^{31-33}$

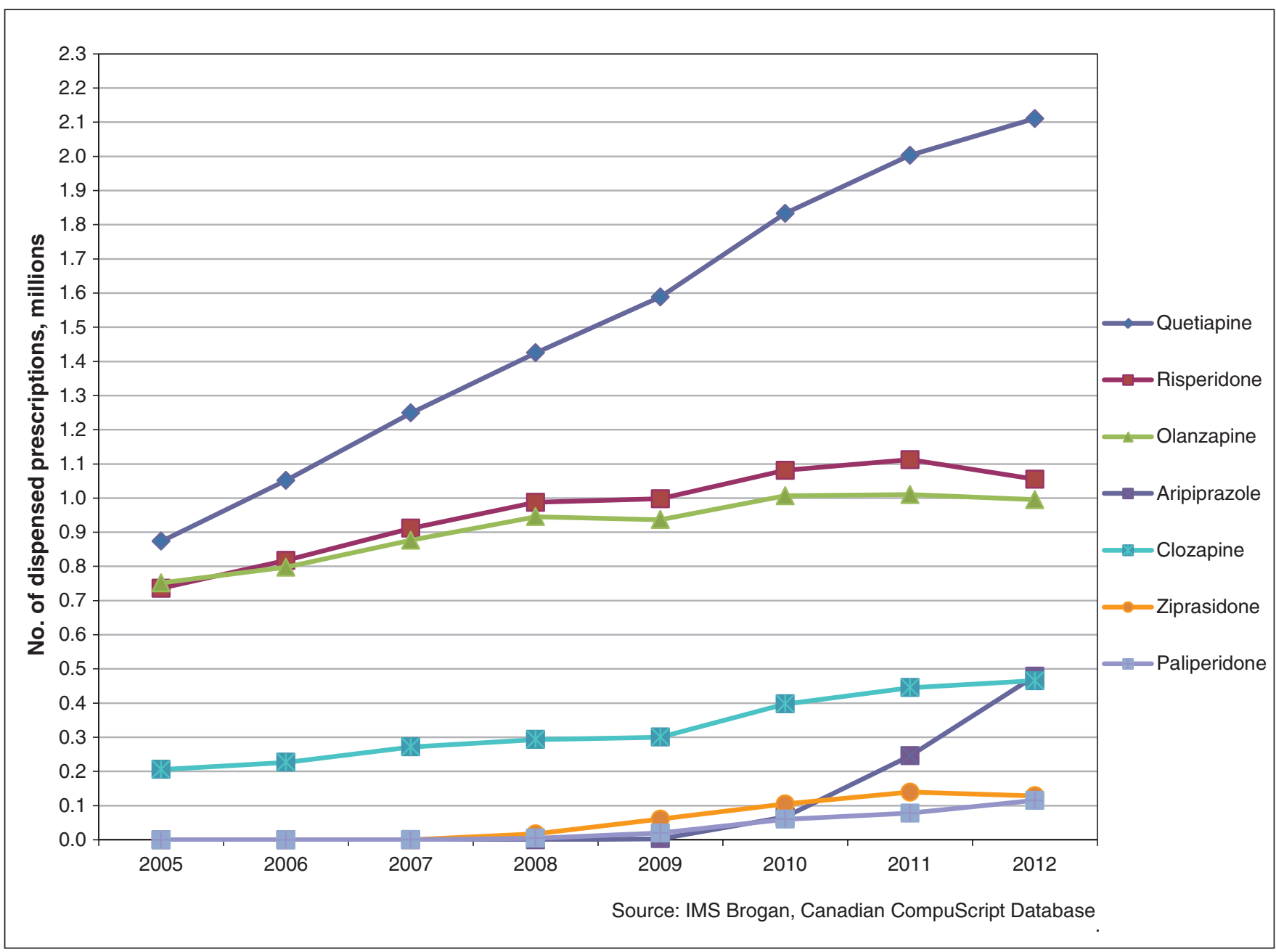

Figure 2: Number of prescriptions for second-generation antipsychotics ordered by psychiatrists, 2005-2012. 
Based on the Canadian Disease and Treatment Index, Patten and colleagues ${ }^{34}$ reported an estimated 108000 recommendations for tricyclic antidepressants and 168000 for trazodone for sleep disturbance in 2005. In 2012, quetiapine reached a similar level of use and, based on trends observed in the Canadian Disease and Treatment Index data, its rate of use is now approaching that of trazodone.

The evidence supporting quetiapine as a hypnotic agent is limited. ${ }^{7}$ Two randomized polysomnographic studies have been conducted. In a study of 16 patients with primary insomnia, baseline characteristics were not balanced: the quetiapine group had notably worse sleep measures. ${ }^{35}$ The study showed no difference between treatment groups after 14 days, possibly as a result of these differences at baseline. In a study of 18 healthy volunteers, all participants were exposed to placebo, quetiapine $25 \mathrm{mg}$ and $100 \mathrm{mg}$ on 2 consecutive nights separated by 4-day intervening washout periods. ${ }^{36}$ Both doses of quetiapine showed an advantage in terms of increased total sleep time (by 30-45 min) and reduced sleep onset latency under noisy conditions (by 15-20 min). However, among patients taking quetiapine, time to achieve slow wave sleep was delayed, and quetiapine was associated with more periodic limb movements. In addition, 2 participants were removed because of fainting when taking $100 \mathrm{mg}$ quetiapine.

It is not known, from controlled trials, whether quetiapine's sedative effects are sustained over time or whether lowdose use provides a favourable risk-benefit ratio compared with alternative sleep aids among patients with nonaffective insomnia. The relative effectiveness, tolerability and safety of quetiapine, compared with other commonly used hypnotics, is a matter of speculation as no direct comparisons have been carried out.

Like all antipsychotics, quetiapine is a common cause of akathisia and a rare cause of neuroleptic malignant syndrome. ${ }^{4,37}$ The risk of developing a severe movement disorder when using quetiapine at lower doses (e.g., 25-150 mg/d) in the treatment of anxiety and sleep disturbance has not been sufficiently investigated. Quetiapine is well recognized for its ability to exacerbate cardiovascular risk factors, including hypertension, dyslipidemia and obesity, even when used at lower doses for insomnia., ${ }^{4,38}$ Less well recognized are risks of severe hepatitis, potentially chronic movement disorders, pneumonia, hypothyroidism and confusion. ${ }^{4,9,39-42}$ Norquetiapine, the major metabolite of quetiapine, is anticholinergic and can produce blurred vision and dry mouth among other anticholinergic side effects. ${ }^{9,14}$ Relevant to its use to treat anxiety and insomnia, quetiapine has been repeatedly associated with withdrawal reactions as well as abuse and dependence. ${ }^{43,44}$

In addition to concerns over the use of quetiapine in treating patients with major depression, anxiety or sleep problems, we have concerns about inadequate monitoring of patients of all ages who are taking quetiapine and other antipsychotics. ${ }^{4,45}$ This issue is most pressing in relation to quetiapine because of its widespread off-label use. ${ }^{46} \mathrm{We}$ suggest that clinicians adhere to published monitoring guidelines when prescribing

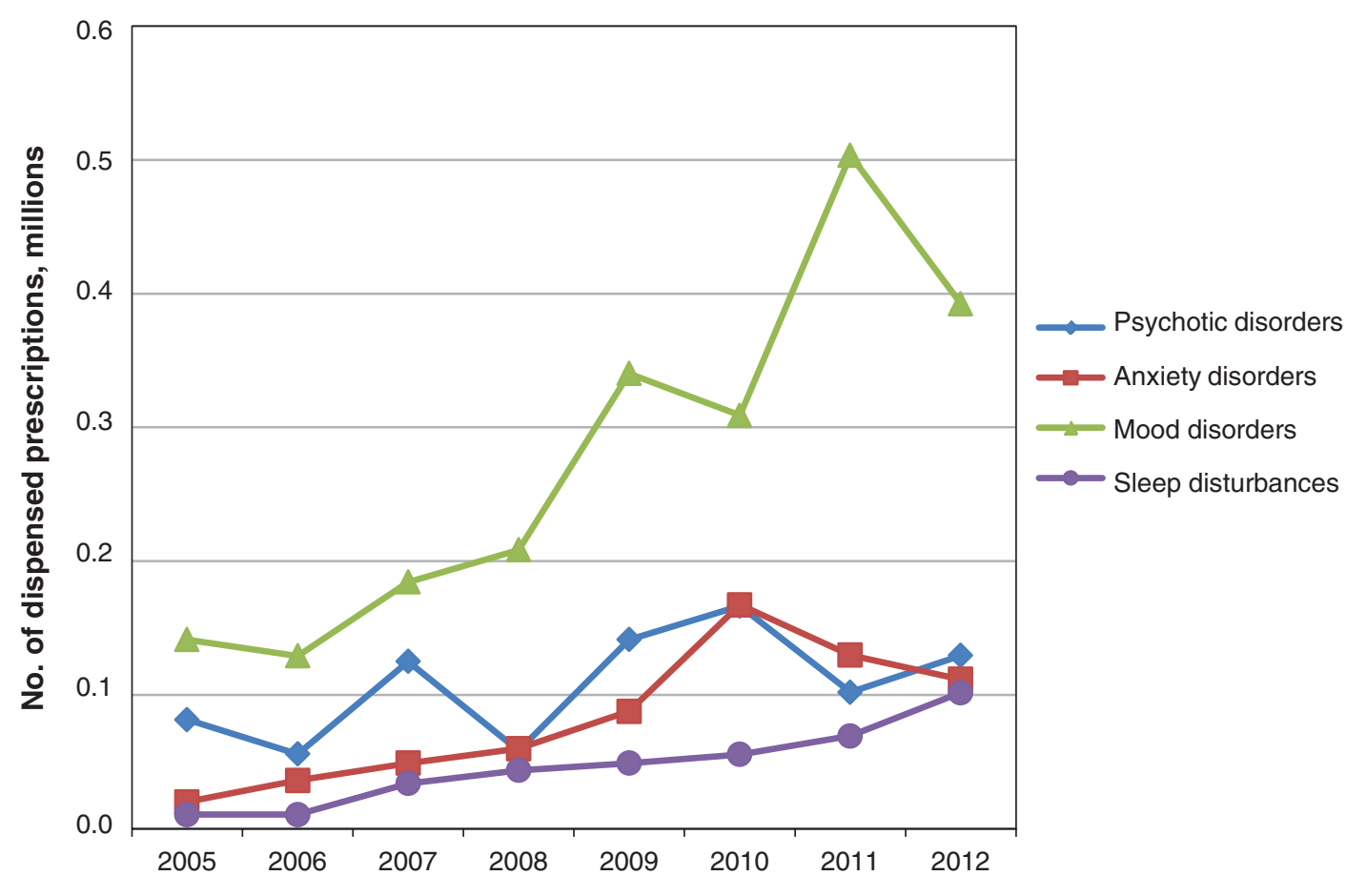

Source: IMS Brogan, Canadian Disease and Treatment Index.

Figure 3: Number of prescriptions for quetiapine, by diagnosis, ordered by primary care physicians, 2005-2012. 
quetiapine, whether for approved indications or off-label uses, regardless of the dose. Depending on the patient, monitoring may include vitals, weight, body mass index, waist circumference, lipid levels, fasting glucose and insulin levels and thyroid-stimulating hormone level. ${ }^{4}$ Moreover, patients should be informed of their treatment options, pharmacologic and nonpharmacologic, and review the related potential harms and benefits.

\section{Limitations}

Limitations on our analysis include the inability to validate information on the appropriateness of second-generation antipsychotic prescribing and the lack of validation information for the IMS Brogan databases. We were also unable to evaluate the age distribution of patients using quetiapine.

\section{Conclusion}

The disproportionate and substantial increase in the use of quetiapine by family physicians over the past decade is of great concern. Knowledge translation strategies are greatly needed to inform physicians about the lack of convincing evidence to support the use of quetiapine for sleep disturbances and anxiety, as well as the risks of harm associated with routine use of this drug.

\section{References}

1. Murphy AL, Gardner DM, Cooke C, et al. Prescribing trends of antipsychotics in youth receiving income assistance: results from a retrospective population database study. BMC Psychiatry 2013;13:198 .

2. Pringsheim T, Lam D, Patten SB. The pharmacoepidemiology of antipsychotic medications for Canadian children and adolescents. 7 Child Adolesc Psychopharmacol 2011;21:537-43.

3. Alessi-Severini S, Biscontri RG, Collins DM, et al. Utilization and costs of antipsychotic agents: a Canadian population-based study, 1996-2006. Psychiatr Serv 2008;59:547-53

4. Gardner DM, Teehan M. Antipsychotics and their side effects. Cambridge: Cambridge University Press; 2010.

5. Alessi-Severini S, Biscontri RG, Collins DM, et al. Ten years of antipsychotic prescribing to children: a Canadian population based study. Can $\mathcal{F}$ Psychiatry 2012;57:52-8.

6. Jing Y, Guo Z, Kalsekar I, et al. Dosing patterns of aripiprazole and quetiapine for adjunctive treatment of major depressive disorder (2006-2010). Int Clin Psychopharmacol 2013;28:87-90.

7. Coe HV, Hong IS. Safety of low doses of quetiapine when used for insomnia. Ann Pharmacother 2012;46:718-22.

8. Seroquel: highlights of prescribing information. Wilmington (DE): AstraZeneca Pharmaceuticals; 2013.

9. Seroquel [product monograph]. Mississauga (ON): AstraZeneca Canada; 2013.

10. Drugs and health products: notice of compliance. Ottawa: Heath Canada; 2012.

11. Seroquel XR [product monograph, US]. Wilmington (DE): AstraZeneca; 2013.

12. Kuehn BM. FDA panel issues mixed decision on quetiapine in depression and anxiety. FAMA 2009;301:2081-2.

13. Is use of quetiapine for sleep evidence-based? Therapeutics Letter 2010;79 September-December. Available: www.ti.ubc.ca/sites/ti.ubc.ca/files/79_0.pdf (accessed 2014 Jul. 14)

14. Jensen NH, Rodriquiz RM, Caron MG, et al. N-desalkylquetiapine, a potent norepinephrine reuptake inhibitor and partial 5-HT1A agonist, as a putative mediator of quetiapine's antidepressant activity. Neuropsychopharmacology 2008;33:2303-12.

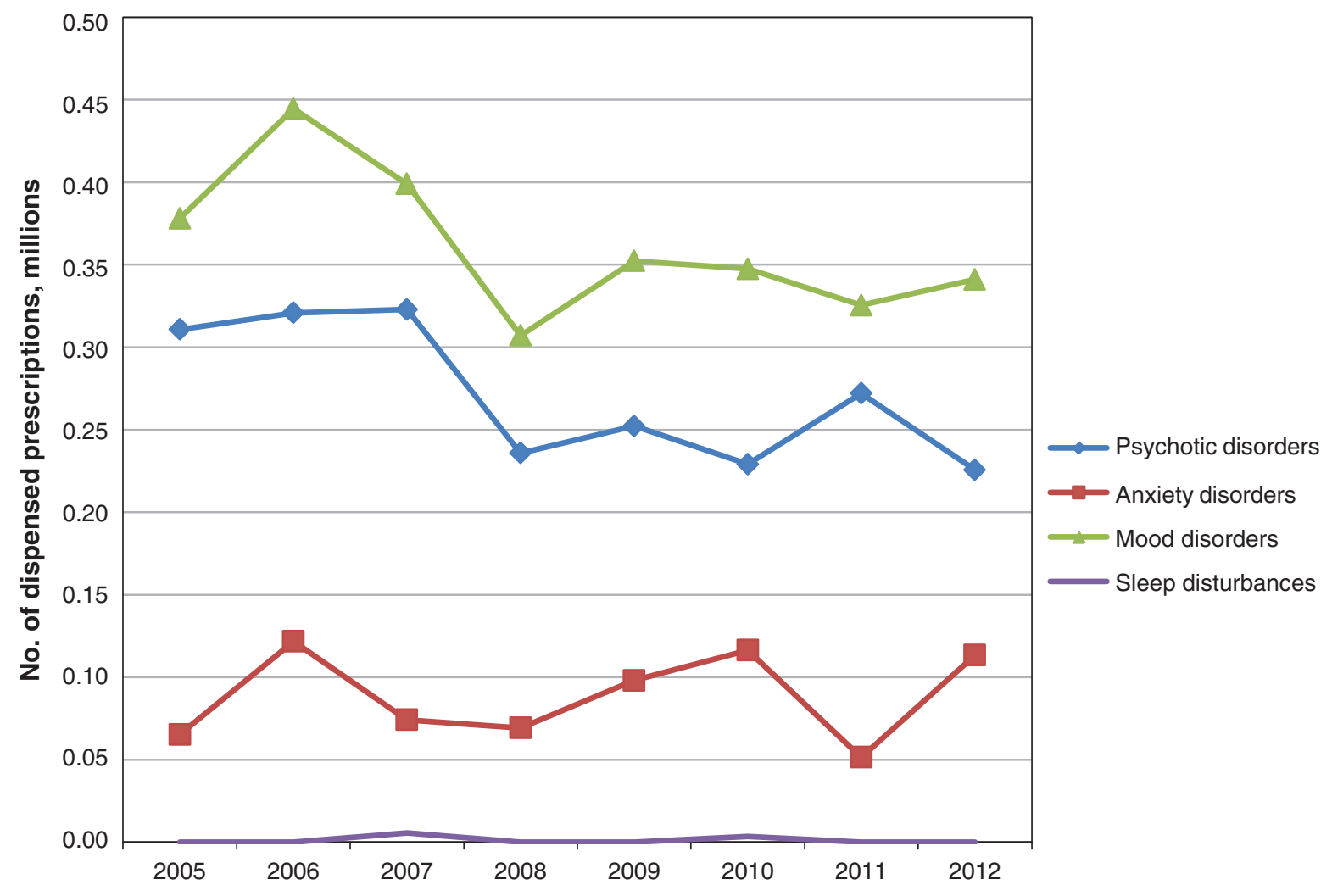

Source: IMS Brogan, Canadian Disease and Treatment Index.

Figure 4: Number of prescriptions for quetiapine, by diagnosis, ordered by psychiatrists, 2005-2012. 
15. Wiegand MH, Landry F, Brückner T, et al. Quetiapine in primary insomnia: a pilot study. Psychopharmacology (Berl) 2008;196:337-8.

16. Pasquini M, Speca A, Biondi M. Quetiapine for tamoxifen-induced insomnia in women with breast cancer. Psychosomatics 2009;50:159-61.

17. Healthcare measurement: Compuscript. In: ims/brogan [website of IMS Health Incorporated]. Available: www.imsbrogancapabilities.com/en/healthcare -compuscript.html (accessed 2014 Sept. 18).

18. Table 051-0001: Estimates of population, by age group and sex for July 1, Canada, provinces and territories. Ottawa: Statistics Canada; 2013. Available: www5.statcan.gc.ca/cansim/a05 ?lang=eng\&id=0510001 (accessed 2014 Mar. 23).

19. Monasterio E, McKean A. Off-label use of atypical antipsychotic medications in Canterbury, New Zealand. N Z Med 7 2011;124:24-9.

20. Philip NS, Mello K, Carpenter LL, et al. Patterns of quetiapine use in psychiatric inpatients: an examination of off-label use. Ann Clin Psychiatry 2008;20:15-20.

21. Komossa K, Depping AM, Gaudchau A, et al. Second-generation antipsychotics for major depressive disorder and dysthmia [review]. Cochrane Database Syst Rev 2010;(12):CD008121.

22. Cipriani A, Koesters M, Furukawa TA, et al. Duloxetine versus other antidepressive agents for depression [review]. Cochrane Database Syst Rev 2012; 10:CD006533.

23. Cutler AJ, Montgomery SA, Feifel D, et al. Extended release quetiapine fumarate monotherapy in major depressive disorder: a placebo- and duloxetine-controlled study. 7 Clin Psychiatry 2009;70:526-39.

24. Vaishnavi S, Alamy S, Zhang W, et al. Quetiapine as monotherapy for social anxiety disorder: a placebo-controlled study. Prog Neuropsychopharmacol Biol Psychiatry 2007;31:1464-9.

25. Simon NN, Connor KM, Le RT, et al. Quetiapine augmentation of paroxetine CR for the treatment of refractory anxiety disorder: preliminary findings. Psychopharmacology (Berl) 2008;197:675-81.

26. Bandelow B, Chouinard $G$, Bobes J, et al. Extended-release quetiapine fumarate (quetiapine XR): a once-daily monotherapy effective in generalized anxiety disorder. Data from a randomized, double-blind, placebo- and activecontrolled study. Int 7 Neuropsychopharmacol 2010;13:305-20.

27. Katzman MA, Brawman-Mintzer O, Reyes EB, et al. Extended release quetiapine fumarate (quetiapine XR) monotherapy as maintenance treatment for generalized anxiety disorder: a long-term, randomized, placebo-controlled trial. Int Clin Psychopharmacol 2011;26:11-24.

28. Khan A, Joyce M, Atkinson S, et al. A randomized, double-blind study of oncedaily extended release quetiapine fumarate (quetiapine XR) monotherapy in patients with generalized anxiety disorder. 7 Clin Psychopharmacol 2011;31:418-28.

29. Merideth C, Cutler AJ, She F, et al. Efficacy and tolerability of extended release quetiapine fumarate monotherapy in the acute treatment of generalized anxiety disorder: a randomized, placebo controlled and active-controlled study. Int Clin Psychopharmacol 2012;27:40-54.

30. Mezhebovsky I, Magi K, She F, et al. Double-blind, randomized study of extended release quetiapine fumarate (quetiapine XR) monotherapy in older patients with generalized anxiety disorder. Data from a randomized, doubleblind, placebo- and active-controlled study. Int 7 Neuropsychopharmacol 2010; 13:305-20.

33. Merideth C, Cutler AJ, She F, et al. Efficacy and tolerability of extended release quetiapine fumarate monotherapy in the acute treatment of generalized anxiety disorder: a randomized, placebo controlled and active-controlled study. Int Clin Psychopharmacol 2012;27:40-54.

34. Patten SB, Esposito E, Carter B. Reasons for antidepressant prescriptions in Canada. Pharmacoepidemiol Drug Saf 2007;16:746-52.

35. Tassniyom K, Paholpak S, Tassniyom S, et al. Quetiapine for primary insomnia: a double blind, randomized controlled trial. 7 Med Assoc Thai 2010;93:729-34.
36. Cohrs S, Rodenbeck A, Gaun Z, et al. Sleep promoting properties of quetiapine in healthy subjects. Psychopharmacology (Berl) 2004;174:421-9.

37. Gortney JS, Fagan A, Kissack JC. Neuroleptic malignant syndrome secondary to quetiapine. Ann Pharmacother 2009;43:785-91.

38. Cates ME, Jackson CW, Feldman JM, et al. Metabolic consequences of using low-dose quetiapine for insomnia in psychiatric patients. Community Ment Health 7 2009;45:251-4.

39. Naharci MI, Karadurmus N, Demir O, et al. Fatal hepatotoxicity in an elderly patient receiving low-dose quetiapine. Am 7 Psychiatry 2011;168: 212-3.

40. Traynor K. FDA advisors wary of expanding quetiapine use: clinicians air concerns about metabolic effects, tardive dyskinesia. Am 7 Health Syst Pharm 2009; 66:880, 882

41. Jeste DV, Jin H, Golshan S, et al. Discontinuation of quetiapine from an NIMH-funded trial due to serious adverse events. Am 7 Psychiatry 2009; 166:937-8.

42. Ramaswamy S, Siddiqui Z, Saharan S, et al. Quetiapine-induced hypothyroidism. 7 Psychiatry Neurosci 2005;30:57.

43. Murphy D, Bailey K, Stone M, et al. Addictive potential of quetiapine. Am $\mathcal{F}$ Psychiatry 2008;165:918.

44. Kim DR, Staab JP. Quetiapine discontinuation syndrome. Am 7 Psychiatry 2005;162:1020.

45. Pringsheim T, Panagiotopoulos C, Davidson J, et al. Evidence-based recommendations for monitoring safety of second generation antipsychotics in children and youth. 7 Can Acad Child Adolesc Psychiatry 2011;20:218-33.

46. McKean A, Monasterio E. Off-label use of atypical antipsychotics: cause for concern? CNS Drugs 2012;26:383-90.

Competing interests: David Gardner reports receiving a grant from Pfizer that is separate from the submitted work. In addition, he is the author of Antipsychotics and Their Side Effects, Cambridge University Press, 2011, for which he received royalties. No other competing interests declared.

Affiliations: Department of Clinical Neurosciences (Pringsheim), University of Calgary, Calgary, Alta.; Department of Psychiatry and College of Pharmacy (Gardner), Dalhousie University, Halifax, NS

Contributors: Tamara Pringsheim contributed substantially to the conception and design of the study, acquisition, analysis and interpretation of data; drafted parts of the article; revised it critically for important intellectual content; gave final approval of the version to be published; and agrees to act as guarantor of the work. David Gardner contributed substantially to the conception and design of the study and interpretation of data; drafted parts of the article; revised it critically for important intellectual content; and gave final approval of the version to be published.

Disclosure: The information contained in this publication is derived in whole or in part from data obtained under license from IMS Brogan (CompuScript and Canadian Disease and Treatment Index audits, 20052013, all rights reserved). The statements, findings, conclusions, views and opinions contained and expressed herein are not necessarily those of IMS Brogan or any of its affiliates.

Supplemental information: For reviewer comments and the original submission of this manuscript, please see www.cmajopen.ca/content/2/4 /E225/suppl/DC1 